www.conferenceie.ase.ro

\title{
A MODEL OF DATABASE PLATFORM FOR E-COMMERCE APPLICATIONS IN E-SOCIETY
}

\author{
Loredana MOCEAN \\ Babes-Bolyai University of Cluj-Napoca, Romania \\ The Faculty of Economic Sciences and Business Administration \\ loredana.mocean@econ.ubbcluj.ro \\ Miranda-Petronella VLAD \\ „Dimitrie Cantemir” Christian University Bucharest, Romania \\ The Faculty of Economic Sciences \\ mirandapv@hotmail.com
}

\begin{abstract}
This paper aims to present a database model for the development of an e-commerce application, a food-ordering/cake shop. Our application is meant to facilitate online ordering of food dishes from suppliers who provide home delivery.
\end{abstract}

Keywords: Database, Electronic Commerce, Implementation, Query

JEL classification: C00, C88, C89

DOI: $10.24818 / \mathrm{ie} 2020.03 .01$

\section{Introduction}

The online environment is developing at an astonishing rate, most of the commerce is carried out in parallel on the Internet and in physical stores. Nowadays we can order almost anything from the Internet, often at lower prices than usual.

First there were electronic good stores, then clothes and accessories stores, and now even food can be found in electronic stores. All of this involves certain logistics costs such as: transport (import or export), packaging, warehousing, delivery, customer relations via email/chat/telephone but also others.

Data is a very powerful organizational resource and it must be managed as such because it reflects on the company's assets, the external environment and the internal environment. The volume of data is constantly increasing and therefore it becomes imminent to organize them into data structures and then databases that can be easily used on the web.

\section{Background}

The technologies associated with e-commerce are used by clients and companies in different ways, which is why companies use them to ease their work.

In what follows we propose an online business model that brings changes in the relationships between partners and customers. It involves innovative technologies and facilitates the ease of online activity.

Minimally, it contains the product catalog or services with technical and commercial descriptions for each position in the catalog. These descriptions are managed by a database management system, which will deal with the storage and manipulation of data and the provision of data access possibilities. The average version contains facilities for taking orders (by e-mail or interactive forms that customers will complete), and the extended version will include the possibility of making the payment online (by credit cards or other electronic versions). 
www.conferenceie.ase.ro

\section{Prototype}

The proposed database is implemented on a pastry/cake shop trading company. The structure of the tables and relationships between them is presented below (see Figure 1). When designing it, we must ensure the flow from producers to consumers. The database is intended to be properly designed, and the programmer can subsequently add new facilities by adding new tables and relating them to existing ones.

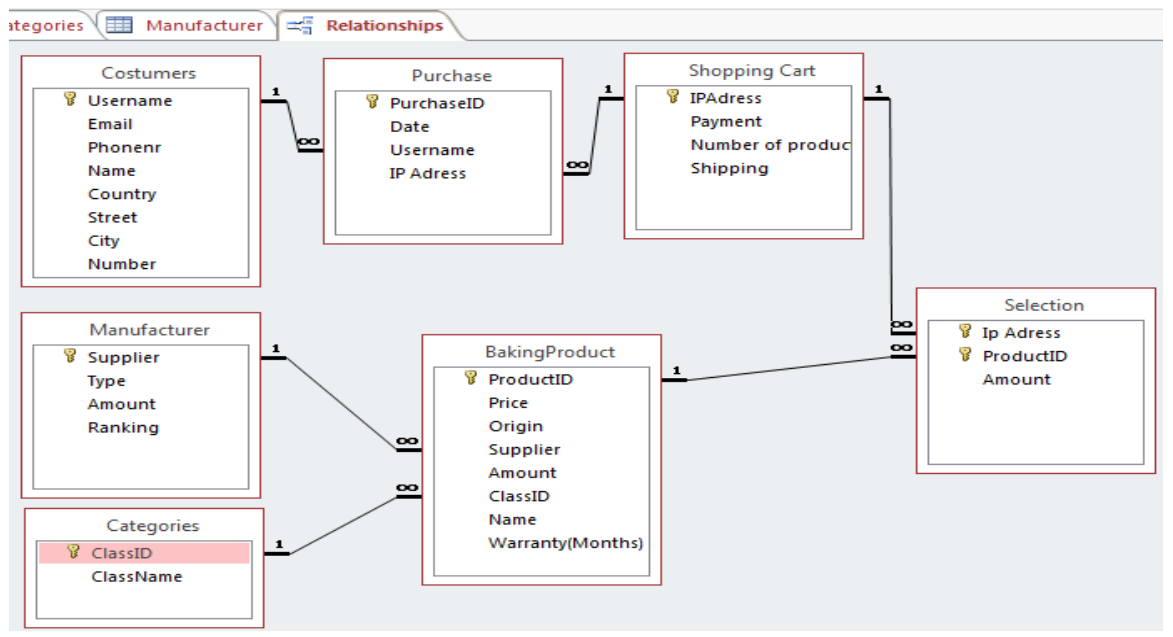

Figure 1. Database relationship

The basic categories and suppliers are shown in the following figures (see Figure 2 and 3).

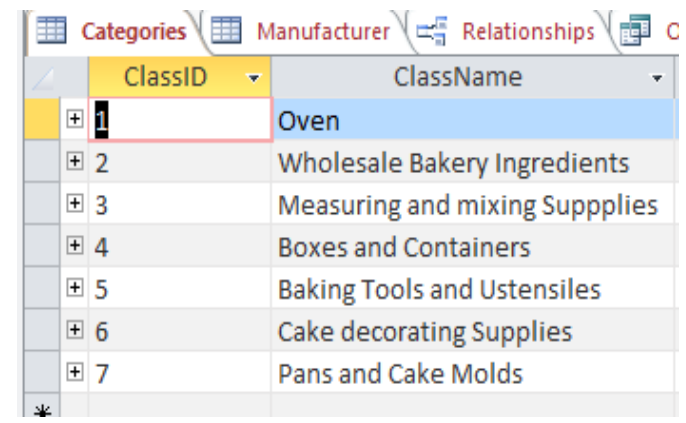

Figure 2. The categories of products

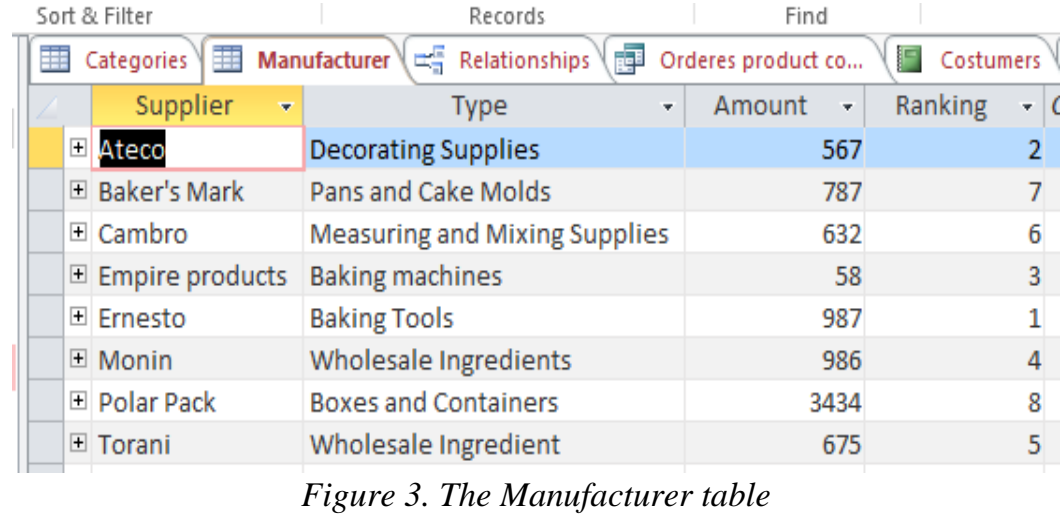

Purchases are recorded in the Purchase table, the invoice is prepared after the PurchaseID primary key field. 
www.conferenceie.ase.ro

\begin{tabular}{|c|c|c|c|}
\hline \multirow{2}{*}{ 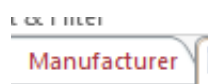 } & \multicolumn{3}{|c|}{ nectuius } \\
\hline & Purchase & & \\
\hline PurchaselD . & Date & Username & IP Adress \\
\hline 200901 & $3 / 8 / 2018$ & kissdia2 & 122.12 .125 .12 \\
\hline 200902 & $3 / 24 / 2018$ & corujanela & 156.56 .456 .36 \\
\hline 200903 & $2 / 7 / 2018$ & brbviv22 & 459.54.459.45 \\
\hline 200904 & $12 / 14 / 2017$ & nagyr3 & 125.36 .963 .35 \\
\hline 200905 & $4 / 20 / 2018$ & petra23 & 126.85 .495 .59 \\
\hline 200906 & $3 / 16 / 2018$ & noemi10 & 124.35 .565 .35 \\
\hline 200907 & $2 / 5 / 2018$ & reka99 & 854.36.459.85 \\
\hline 200908 & $1 / 10 / 2018$ & liptai67 & 456.23.458.99 \\
\hline 200909 & $4 / 29 / 2018$ & gabo2000 & 123.52.981.11 \\
\hline
\end{tabular}

Figure 3. Purchase Table, the structure and a few orders.

The Selection table is used to select products from a particular IP. We present the structure and some recordings (see Figure 4).

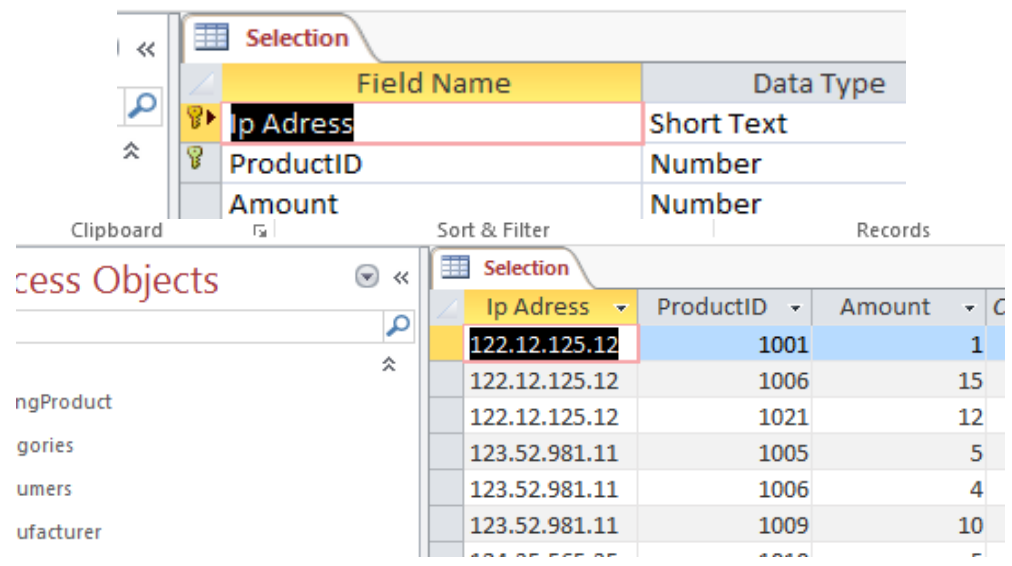

Figure 4. The structure and a few records of Selection table

\section{Data retrieval}

In a well-designed database, queries help us extract information from various tables and assemble them to display in the form or report. Thus, the user will focus much better only on the information he needs. A database management system requires a query language to allow the user to access the data. SQL is the language used by most relational database systems, so we will also exemplify the queries proposed in this language.

A first query would be required to display the cost of the products ordered by a particular person. We can write a query with the code below.

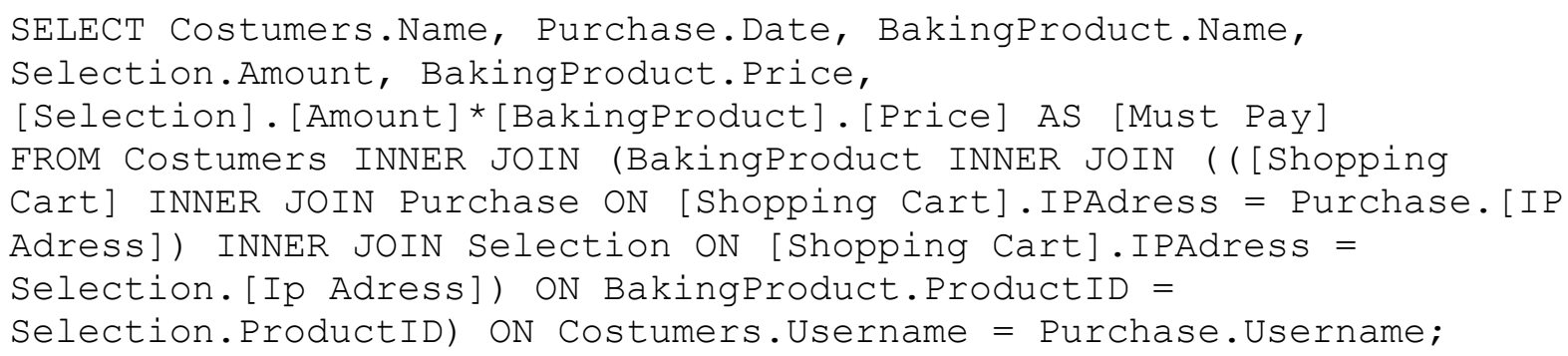

The result of the code is shown in Figure 5. 


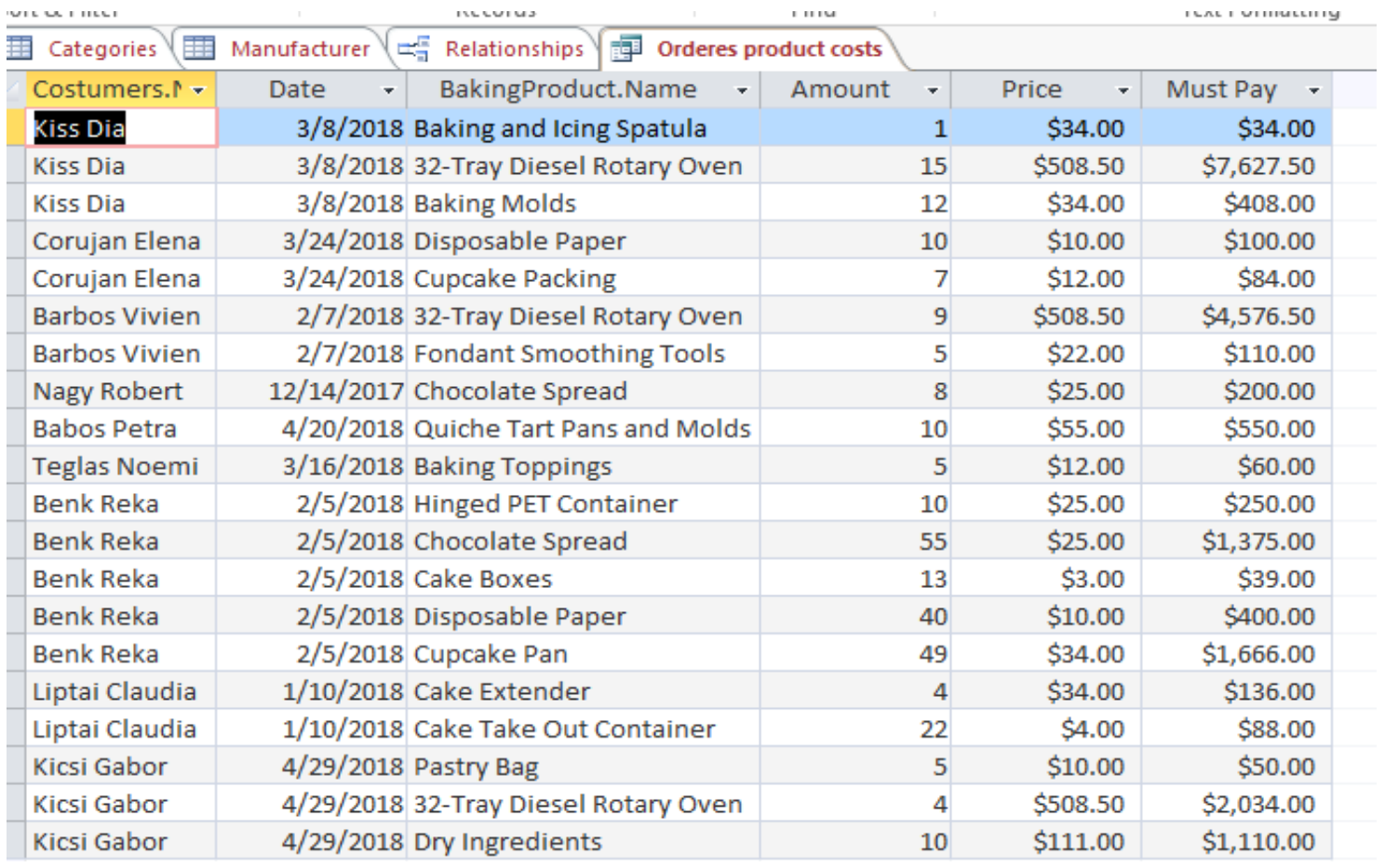

Figure 5. An important query : Orderes Products costs

We can use arithmetic operators to create our own expressions in queries. For example to apply a discount of $9 \%$ we can write the query with the code below.

UPDATE BakingProduct SET BakingProduct.Price = Price*0.9 WHERE $((($ BakingProduct. [ClassID] $)=" 1 ")$ AND BakingProduct. [Price] $)>=100))$;

To generate a report showing us the buyers' products we can write the query below.

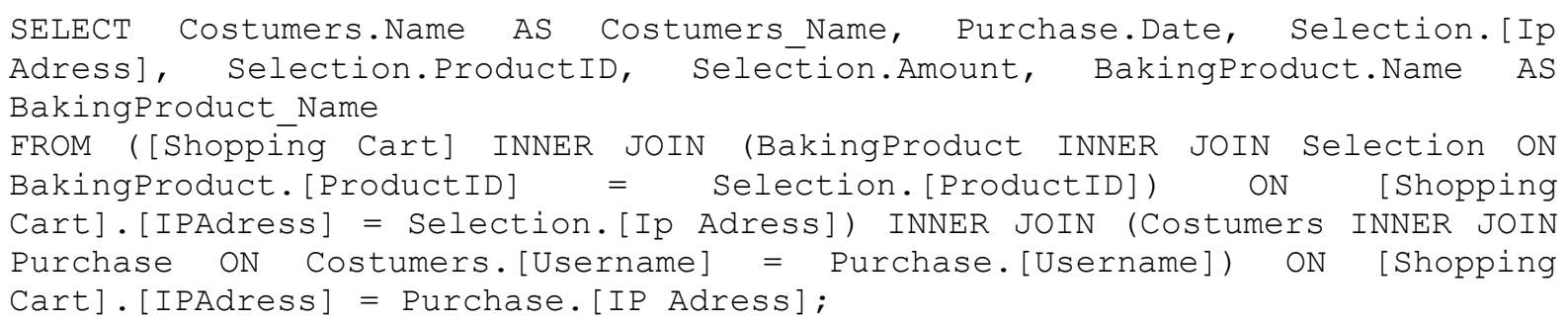

Then the report can be generated, as shown in Figure 6.

SQL being a powerful language for relational databases used in querying, updating and managing data, will also help to write a query that provides us with product information. We will first write the query in SQL code, then we will build the report based on the query (as shown in Figure 7). 
Proceedings of the IE 2020 International Conference

www.conferenceie.ase.ro

\begin{tabular}{|c|c|c|c|c|c|}
\hline \multicolumn{6}{|l|}{ Costumers } \\
\hline \multirow{2}{*}{$\begin{array}{l}\text { Costumers_Name } \\
\text { Babos Petra }\end{array}$} & \multicolumn{2}{|c|}{ Date Ip Adress } & \multicolumn{3}{|c|}{ ProductID Amount BakingProduct_Name } \\
\hline & $4 / 20 / 2018$ & 126.85 .495 .59 & 1018 & 10 & Quiche Tart Pans and Molds \\
\hline \multicolumn{6}{|l|}{ Barbos Vivien } \\
\hline & $2 / 7 / 2018$ & 459.54 .459 .45 & 1006 & 9 & 32-Tray Diesel Rotary Oven \\
\hline & $2 / 7 / 2018$ & 459.54 .459 .45 & 1003 & 5 & Fondant Smoothing Tools \\
\hline \multicolumn{6}{|l|}{ Benk Reka } \\
\hline & $2 / 5 / 2018$ & 854.36 .459 .85 & 1028 & 10 & Hinged PET Container \\
\hline & $2 / 5 / 2018$ & 854.36 .459 .85 & 1012 & 55 & Chocolate Spread \\
\hline & $2 / 5 / 2018$ & 854.36 .459 .85 & 1022 & 13 & Cake Boxes \\
\hline & $2 / 5 / 2018$ & 854.36 .459 .85 & 1025 & 40 & Disposable Paper \\
\hline & $2 / 5 / 2018$ & 854.36 .459 .85 & 1029 & 49 & Cupcake Pan \\
\hline \multicolumn{6}{|l|}{ Corujan Elena } \\
\hline & $3 / 24 / 2018$ & 156.56 .456 .36 & 1024 & 7 & Cupcake Packing \\
\hline & $3 / 24 / 2018$ & 156.56 .456 .36 & 1025 & 10 & Disposable Paper \\
\hline \multicolumn{6}{|l|}{ Kicsi Gabor } \\
\hline & $4 / 29 / 2018$ & 123.52 .981 .11 & 1009 & 10 & Dry Ingredients \\
\hline & $4 / 29 / 2018$ & 123.52 .981 .11 & 1005 & 5 & Pastry Bag \\
\hline & $4 / 29 / 2018$ & 123.52 .981 .11 & 1006 & 4 & 32-Tray Diesel Rotary Oven \\
\hline \multicolumn{6}{|l|}{ Kiss Dia } \\
\hline & $3 / 8 / 2018$ & 122.12 .125 .12 & 1001 & 1 & Baking and Icing Spatula \\
\hline & $3 / 8 / 2018$ & 122.12 .125 .12 & 1021 & 12 & Baking Molds \\
\hline & $3 / 8 / 2018$ & 122.12 .125 .12 & 1006 & 15 & 32-Tray Diesel Rotary Oven \\
\hline \multicolumn{6}{|l|}{ Liptai Claudia } \\
\hline & $1 / 10 / 2018$ & 456.23 .458 .99 & 1020 & 4 & Cake Extender \\
\hline \multirow{2}{*}{\multicolumn{6}{|c|}{22 Cake Take Out Container }} \\
\hline & & & & & \\
\hline & $12 / 14 / 2017$ & 125.36 .963 .35 & 1012 & 8 & Chocolate Spread \\
\hline Teglas Noemi & & & & & \\
\hline
\end{tabular}

Figure 6. Buyers products (report and query builder)

SELECT Manufacturer.Supplier, BakingProduct. Name, BakingProduct.Price, BakingProduct.Amount, BakingProduct. [Warranty(Months)] FROM Manufacturer INNER JOIN BakingProduct ON Manufacturer.[Supplier] = BakingProduct.[Supplier];

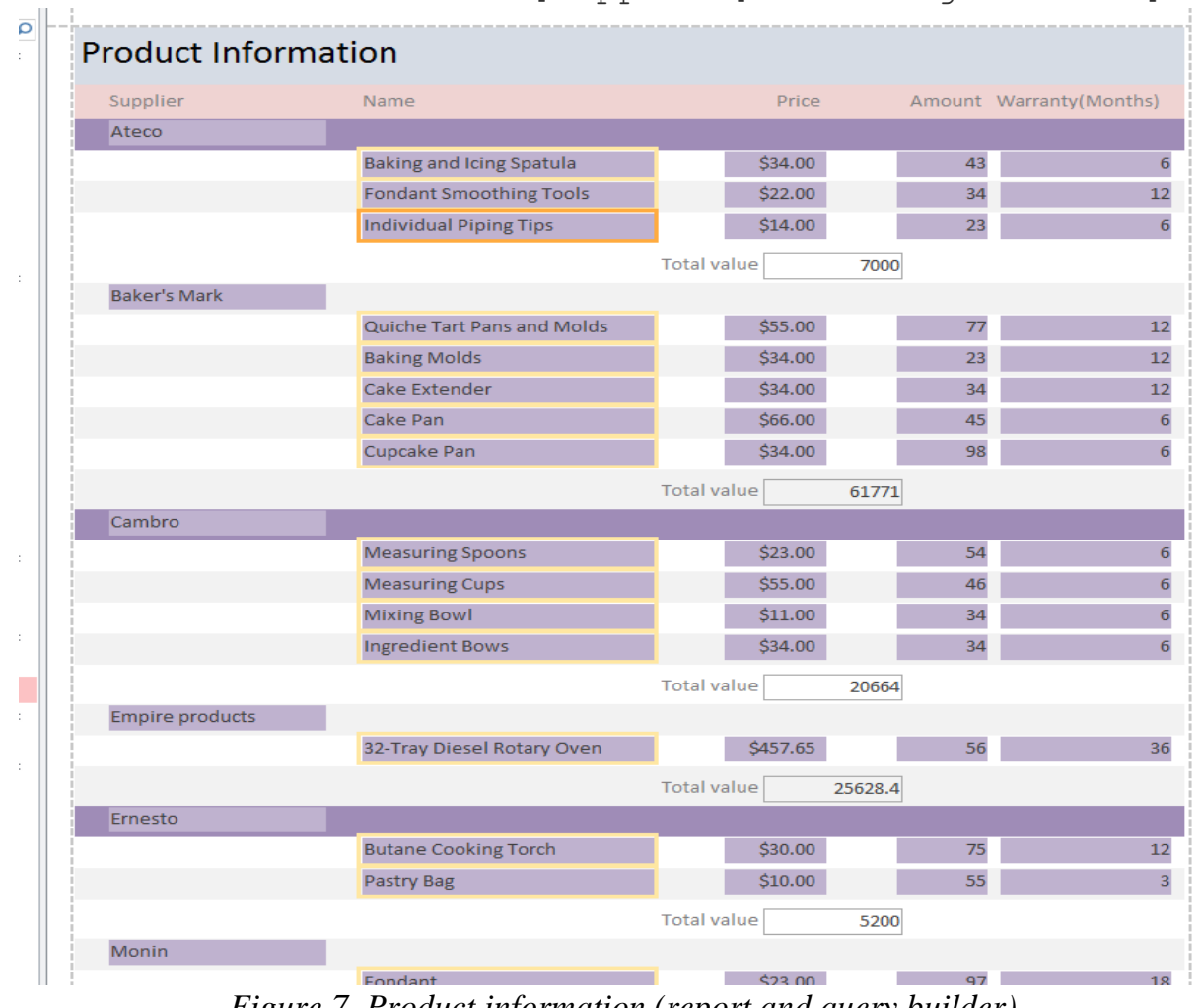

Figure 7. Product information (report and query builder) 
www.conferenceie.ase.ro

After the basic tables are created, it is necessary to create a table to manage the shopping cart. The usual operations in such situations are: adding products, removing a product or a piece of a product, emptying the shopping cart.

The table structure is made in accordance with the application requirements and includes the following fields with the corresponding properties (see Table 1).

Table 1. The structure of Shipping Cart table

\begin{tabular}{|l|l|l|}
\hline Field Name & Field Type & Properties \\
\hline IPAdress & Short Text & Indexed, Primary key, No Duplicates \\
\hline Payment & Short Text & LookupWizard, Cash / Card \\
\hline Number of Product & Number & Whole number \\
\hline Shipping & Short Text & Free / Costs \\
\hline
\end{tabular}

Some examples from the table that manages the shopping cart data are shown in figure 8 .

\begin{tabular}{|c|c|c|c|c|c|c|}
\hline \multicolumn{3}{|c|}{ Sort \& Filter } & \multicolumn{2}{|r|}{ Records } & & . \\
\hline 贯 & Categories 困 & Manufacturer & Ex & Relationships & 國 & Orderes prod \\
\hline & IPAdress & Payment & $\checkmark$ & Number of $\mathrm{F}$ & c. & Shipping \\
\hline+ & 122.12 .125 .12 & Card & & & 5 & Free \\
\hline+ & 123.52 .981 .11 & - Card & & & 43 & Free \\
\hline+ & 124.35 .565 .35 & Cash & & & 76 & Free \\
\hline+ & 125.36 .963 .35 & Card & & & 23 & Free \\
\hline + & 126.85 .495 .59 & Card & & & 16 & Free \\
\hline+ & 156.56 .456 .36 & Cash & & & 4 & Free \\
\hline+ & 456.23 .458 .99 & Card & & & 23 & Free \\
\hline+ & 459.54 .459 .45 & Cash & & & 19 & Free \\
\hline+ & 854.36 .459 .85 & Cash & & & 30 & Free \\
\hline
\end{tabular}

Figure 8. Shipping Cart

\section{Conclusions}

Nowadays, even a very small e-commerce store on a custom platform already uses a database. There is so much information that a store processes, that it is impossible not to use a database. This is the reason why for our online store business we have chosen to design the database and build the application ourselves. We considered that our application would provide some of the following features: easy to make changes, cakes detail pages, online support, contact forms, animation on pages, e-commerce features, easy making changes to the site.

With regard to databases, the present work aims to be an example of several branches in this field: database description, SQL programming and VBA programming. Through this combination we tried to integrate information, centralize it and extract results to be processed. The current technologies existing in both electronic commerce and in the field of databases promote decentralized, web-based work, managing to achieve the most profitable compromise.

\section{References}

[1] L. Mocean and D.A. Sitar_Tăut, Baze de date. Fundamente teoretice și exemplificări în Microsoft Access, Ed. Risoprint 2017

[2] L. Mocean (coord.), Baze de date și programare, Ed. Risoprint, 2017

[3] L. Mocean, Programarea aplicațiilor Access, Ed. Risoprint, 2011.

[4] C. Adam, Comert electronic și marketing online, Ed. Eurobit, 2012

[5] M. Coros., A.M. pop s.a., Vineyards and Wineries in Alba County, Romania towards Sustainable Business Development”, Sustainability (ISSN: 2071-1050) MDPI Journal 